\title{
UM ACERVO AUTOBIOGRÁFICO: A CAPOEIRA DOS MESTRES PASTINHA, BIMBA E COBRINHA VERDE NO MUSEU AFRO-BRASILEIRO DA UNIVERSIDADE FEDERAL DA BAHIA
}

\section{JOSEANIA MIRANDA DE FREITAS}

Universidade Federal da Bahia

\section{MARCELO NASCIMENTO BERNARDO DA CUNHA}

Universidade Federal da Bahia

RESUMO Este texto faz referência a um processo de pesquisa museal, no qual elementos da cultura material e imaterial foram documentados, revelando a existência do acervo autobiográfico de três importantes mestres da capoeira, na cidade de Salvador. A prática da pesquisa documental envolveu diversos procedimentos metodológicos, a exemplo da pesquisa bibliográfica, da tomada de depoimentos e do grupo focal, revelando determinadas tramas das relações sociais e políticas pelas quais os sujeitos e os objetos se constituíram. Entrelaçando a produção dos acervos individuais, sua utilização e a salvaguarda dos mesmos, o texto apresenta suas principais marcas identitárias, possibilitando a abertura de outros campos de investigação sobre histórias de vida, a partir do estudo de objetos e coleções, registros corporais e materiais das memórias afro-brasileiras. Palavras-chave: Capoeira. Biografia. Estudo de objetos. Museu.

\section{ABSTRACT AN AUTOBIOGRAPHICAL COLLECTION: THE CAPOEIRA OF MASTERS PASTINHA, BIMBA AND COBRINHA VERDE IN THE AFRO-BRAZILIAN MUSEUM OF THE FEDERAL UNIVERSITY OF BAHIA}

This text refers to a process of museological research, in which the material and immaterial culture elements were documented, revealing the existence of autobiographical collection of three important masters of capoeira in Salvador. The practice of documentary research involved various methodological procedures, such as literature research, testimonials and focus groups, revealing certain plots 
of social and political relations in which the subjects and objects are constituted. Intertwining the production of personal collections, their use and their safeguard, the text presents its main identity marks, allowing the opening of other fields of research on life stories from the study of objects and collections, physical records and materials of african-Brazilian memories.

Keywords: Capoeira. Biography. Study of objects. Museum.

\section{RESUMEN UNA COLECCIÓN AUTOBIOGRÁFICA: LA CAPOEIRA DE LOS MAESTROS PASTINHA, BIMBA Y COBRINHA VERDE EN EL MUSEO AFRO-BRASILEÑO DE LA UNIVERSIDAD FEDERAL DE BAHÍA}

Este texto se refiere a un proceso de investigación museológica en el que elementos de la cultura material e inmaterial fueron documentados, revelando la existenciade la colección autobiográfica de tres importantes maestros de capoeira en la ciudad de Salvador. La práctica de la investigación documental involucró diversos procedimientos metodológicos, como la revisión bibliográfica, la toma de testimonios y el grupo focal, mostrandodeterminadas tramas de las relaciones sociales y políticas en las que se constituyeron los sujetos y objetos. Entrelazando la producción de las colecciones individuales, su uso y salvaguardia, el texto presenta sus principales marcas identitarias, posibilitando la apertura de otros campos de indagación sobre historias de vida a partir del estudio de los objetos y colecciones, registros corporales y materiales de las memorias afro-brasileñas.

Palabras clave: Capoeira. Biografía. Estudio de objetos. Museo.

Parece redundante, mas é necessário não esquecer que os objetos e/ou artefatos estão carregados de vida, que histórias de vidas podem ser lembradas e/ou esquecidas, narradas e/ou silenciadas, registradas e/ou descartadas, a partir do estudo dos objetos. Muitas vezes, esquecemo-nos da potência vital dos objetos e, dicotomicamente, retiramos a vida humana que ali está impregnada, separando dimensões que se complementam. Objetos são produções humanas, estão carregados de informações, sintetizam trajetórias de vida, assim como são, em si, informação e documento. No entanto, faz-se necessário estabelecer pro- cessos de pesquisa para que se possa "escutar as vozes" dos objetos, buscando compreendê - los material e simbolicamente. No processo de "escuta" é preciso ter em conta as palavras de Meneses (1998, p. 2), baseadas em Radley (1990), “[...] a simples durabilidade do artefato, que em princípio costuma ultrapassar a vida de seus produtores e usuários originais, já o torna apto a expressar o passado de forma profunda e sensorialmente convincente [...]". A "escuta" produz uma "fala", como também salienta Meneses:

O historiador não faz o documento falar: é o historiador quem fala e a explicitação de seus 
critérios e procedimentos é fundamental para definir o alcance de sua fala. Toda operação com documentos, portanto, é de natureza retórica. Não há por que o documento material deva escapar destas trilhas, que caracterizam qualquer pesquisa histórica. (MENESES, 1998, p. 7)

O estudo dos objetos dos mestres de capoeira, de forma intrínseca e extrínseca, constitui-se em caminho para a construção de uma retórica institucional, através da comunicação museológica, de forma polifônica e polissêmica. A capoeira evoca memórias ancestrais, memórias que se expressam no campo simbólico, por meio das lembranças e memórias no campo tangivel, impregna- das nos objetos, como sinalizam as palavras de Meneses (1998, p. 90): “A natureza física dos objetos materiais traz marcas específicas à memória". A força dessas marcas tornase matéria-prima para a elaboração de uma série de análises que entrelaçam a vida dos Mestres às peças das coleções, especialmente quando em um museu.

Falar sobre um acervo museológico autobiográfico significa falar da relação intrínseca e extrínseca dessa coleção com os seus proprietários e produtores - os Mestres de Capoeira Pastinha (Vicente Joaquim Ferreira Pastinha), Bimba (Manoel dos Reis Machado) e Cobrinha Verde (Rafael Alves França).

Imagens 1, 2 e 3 - Mestre Pastinha, Mestre Bimba e Mestre Cobrinha Verde

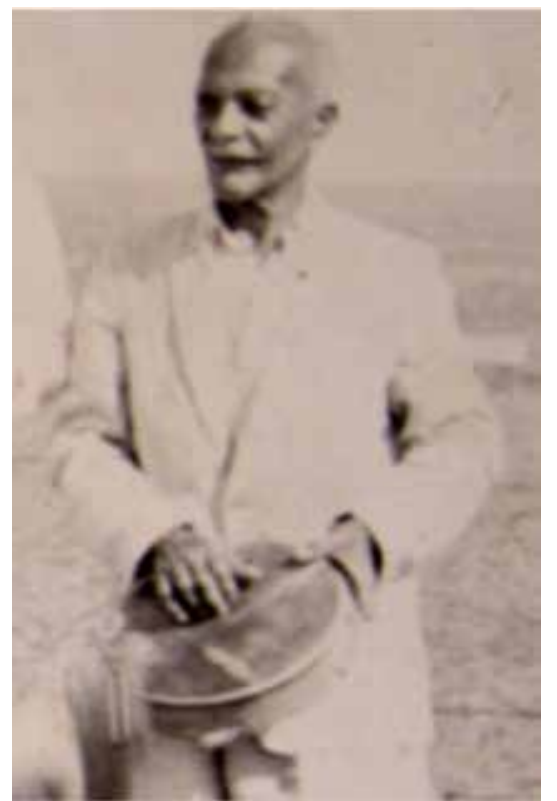

(Acervo do MAFRO/UFBA).
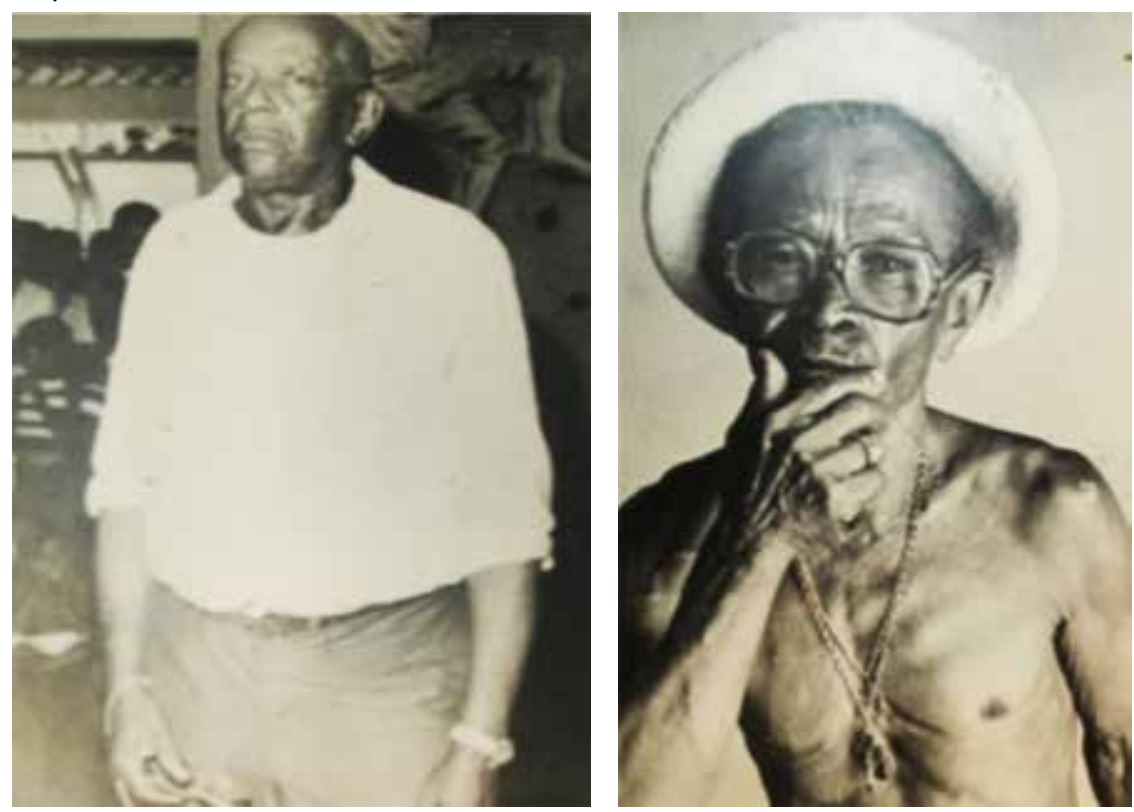

O acervo destaca dois aspectos importantes na formação dos conjuntos de objetos dos Mestres. Primeiro, eles estavam atentos ao registro da prática da capoeira, cada um a sua maneira estava atento à "escrita de si", escrita que emerge "[...] em um contexto intelectual de valorização da subjetividade e das experiências privadas [...] o conceito de 'si mesmo' é, como todo conceito, uma proposta organi- zadora de determinado princípio de racionalidade [...]" (SOUZA, 2007, p. 68). Cada "escrita de si" envolve um "si" coletivo, implicado às memórias ancestrais e às gerações futuras, através da guarda de documentos, quer objetos tridimensionais ou registros em suporte papel, como fotografias, fotomontagens, carteiras das academias, registros de alunos, livros e papéis diversos. 
O segundo aspecto está no cuidado dos familiares $^{1}$ e de um amigo, ${ }^{2}$ em reunir e entregar os objetos para a salvaguarda, em uma instituição oficial de registro de memórias, o Museu Afro-Brasileiro da Universidade Federal da Bahia, entre os anos de 1983 e 1984. Nos dois aspectos, fica evidente não somente a sensibilidade, mas, principalmente, a explicitação de uma lógica preservacionista, baseada na importância dos objetos para a compreensão das trajetórias biográficas. Esses aspectos, portanto, não são omitidos no trabalho museal, pois caracterizam a dinâmica do trabalho de pessoas comprometidas com as formas de registro dessas peças, muito antes da transformação dos conjuntos de objetos em acervo museológico e biográfico.

Ao iniciar o processo de pesquisa para a produção do livro-catálogo Uma coleção biográfica: os Mestres Pastinha, Bimba e Cobrinha Verde, no Museu Afro-Brasileiro da UFBA - revisando as fichas de documentação, percebemos que a Coleção de Capoeira estava composta por 104 objetos e que, destes, 70 pertenciam aos Mestres Pastinha, Bimba e Cobrinha Verde, o que lhes conferiu um caráter autobiográfico. ${ }^{3}$ Esses Mestres são reconhecidos por terem vivido a chamada "época de ouro" da capoeira baiana, quando a mesma saiu da condição de prática marginal e passou a ser ensinada em academias legalizadas. Os objetos estiveram em exposição até 1995 (imagem 4), momento em que o Museu passou pela primeira reestruturação da exposição de longa duração. Essa reestruturação durou dois anos, orquestrada por um projeto que incluía a instalação da Sala da Herança Afro-Brasileira, pensada para dar destaque às coleções de Capoeira, Irmanda-

1 Maria Romélia da Costa e Júlio Alves Filho, para as coleções dos Mestres Pastinha e Cobrinha Verde, respectivamente.

2 Raimundo César de Almeida, Mestre Itapuã, para a coleção do Mestre Bimba.

3 Sendo 23 do Mestre Pastinha, 21 do Mestre Bimba e 26 do Mestre Cobrinha Verde. des, Quilombos, Movimentos Negros, Afoxés e Blocos Afro. No entanto, a época foi marcada pela perda de espaços físicos nas instalações gerais do Museu, não comportando a sala destinada às coleções citadas. Por esse motivo, os objetos foram acondicionados e armazenados na Reserva Técnica. ${ }^{4}$

\section{Imagem 4 - Antiga Exposição}

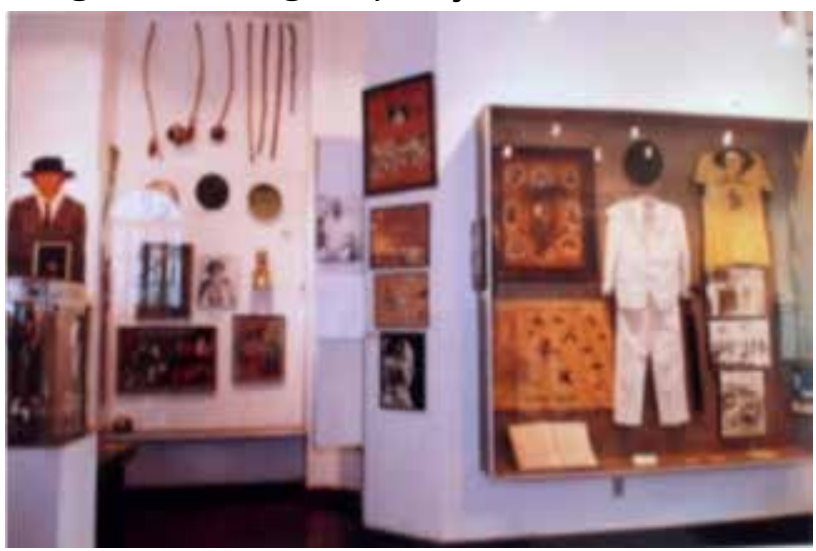

(Acervo do MAFRO/UFBA).

Uma das marcas do ser humano é a sua capacidade para produzir artefatos, ou seja, transformar matérias-primas em diversificados objetos, que circulam "[...] significativamente em nossa vida social, por intermédio das categorias culturais ou dos sistemas classificatórios dentro dos quais os situamos, separamos, dividimos e hierarquizamos" (GONÇALVES, 2007, p. 14). Quando retirados de seu contexto original, para o qual foram concebidos, eles perdem a sua relação funcional, sem, no entanto, estarem dissociados das relações sociopolíticas para as quais foram produzidos. Uma das características dos museus é trabalhar com conjuntos de objetos e/ou artefatos que perderam as suas funções, mas que continuam sendo portadores de informações: algumas delas intrínsecas, presentes fisicamente nos próprios objetos e/ ou artefatos, e muitas outras extrínsecas, ad-

4 A nova Reserva Técnica, que atende aos padrões técnicos, foi inaugurada em 2009, através de um projeto de apoio do BNDES. Mais informações sobre o MAFRO, disponiveis em: <http://www.mafro.ceao.ufba.br>. Acesso em: 01 jul. 2016. 
vindas da trama de relações que o processo de pesquisa pode oferecer.

0 trabalho de pesquisa revelou determinadas tramas das relações sociais e políticas pelas quais os sujeitos e os objetos se constituíram, seja de forma isolada ou em conjunto. Revelou ainda as marcas identitárias de quem os produziu, os utilizou e os salvaguardou, possibilitando também a abertura de outros campos de investigação, a exemplo dos contextos que levam à explicitação dos tempos e espaços com os quais as peças estabeleceram - e ainda estabelecem - relações. Ao se trabalhar com memórias e tempos, são reveladas dinâmicas retrospectivas e prospectivas, como salientam as palavras de Souza (2007, p. 63):

Trabalhar com a memória, seja a memória institucional ou a do sujeito, faz emergir a necessidade de se construir um olhar retrospectivo e prospectivo no tempo e sobre o tempo reconstituído como possibilidade de investigação [...] A memória é escrita num tempo, um tempo que permite deslocamento sobre as experiências [...].

No caso específico do estudo das peças dos Mestres Pastinha, Bimba e Cobrinha Verde, coube à equipe de pesquisa o trabalho de tecer argumentos que pudessem levar à compreensão dos diversos contextos vividos pelos Mestres, de forma a descobrir informações sobre a vida das peças, antes de sua transformação em acervo museológico. Como exemplo do caráter indissociável entre as memórias e a materialidade dos objetos e/ou artefatos, é possivel citar o caso do estudo de um berimbau policromado do Mestre Pastinha (imagem 5). Após algumas reflexões, ouvindo pessoas que conviveram com o capoeirista, foi possivel inferir que o mesmo pode ter sido um presente, alusivo às cores utilizadas na sua Academia, ${ }^{5}$ uma vez que ele não utilizava pinturas, afirmando que a pigmentação poderia interferir na qualidade do som do instrumento.

5 Preto e amarelo, cores do seu time de futebol, o Ypiranga.
Imagem 5 - Berimbau da Academia de Mestre Pastinha

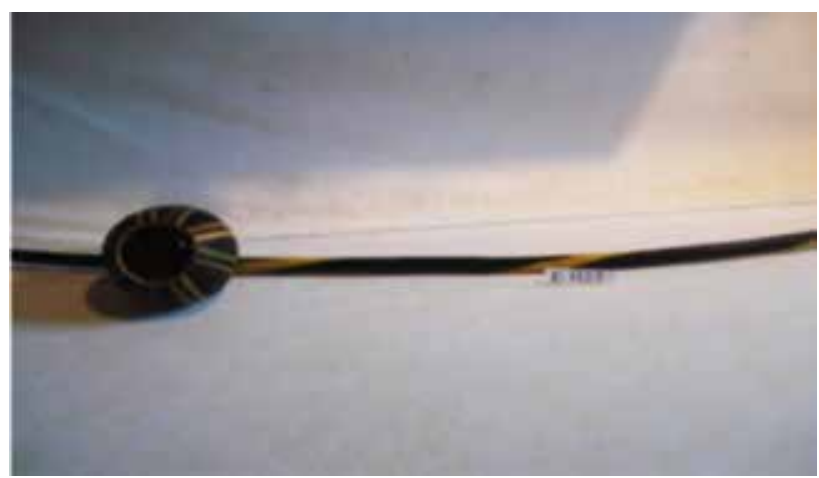

(Acervo do MAFRO/UFBA).

O estudo das peças da coleção exigiu o estabelecimento de nexos entre os objetos e/ou artefatos, produtos da cultura material, e as diversas memórias, registradas ou não, sobre a vida de cada mestre, sobre a formação das coleções em cada família, amigo e suas diversas histórias, individuais e coletivas, e a consequente transformação das peças em objetos museológicos. A produção do livro-catálogo (imagem 6) resultou de anos de investigação, com o apoio da Pró-Reitoria de Pesquisa, com bolsas de Iniciação Científica - PIBIC/UFBA, $\mathrm{PIBIC/CNPq}$ e PIBIC/FAPESB - para alunos da graduação em Museologia, nos seguintes períodos: 2003-2004, 2011-2012, 2012-2013 e 20132014. Para a efetiva publicação, contou com o apoio financeiro do Edital de Museus, do Fundo de Cultura - SECULT/IPAC/DIMUS/2014.

Imagem 6 - Capa do livro-catálogo

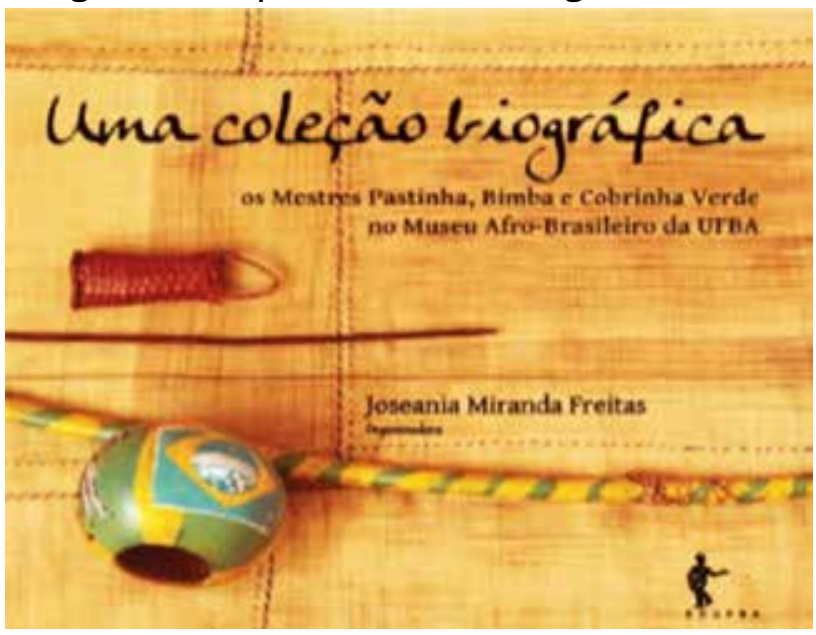

(Acervo do MAFRO/UFBA). 
A Coleção Mestre Pastinha é composta por 23 peças. Este mestre, que nasceu em 1889, foi marcadamente um homem do seu tempo: trabalhou pela efetiva conquista da abolição, que existia por lei, mas que na vivência cotidiana precisava ser conquistada a cada dia. Sua ca- poeira, batizada Capoeira Angola, apresentava no nome uma referência explícita ao continente africano e à história da escravidão, motivos pelos quais as peças de sua coleção expressam a necessidade do Mestre provar para a sociedade o caráter cívico de brasilidade da capoeira.

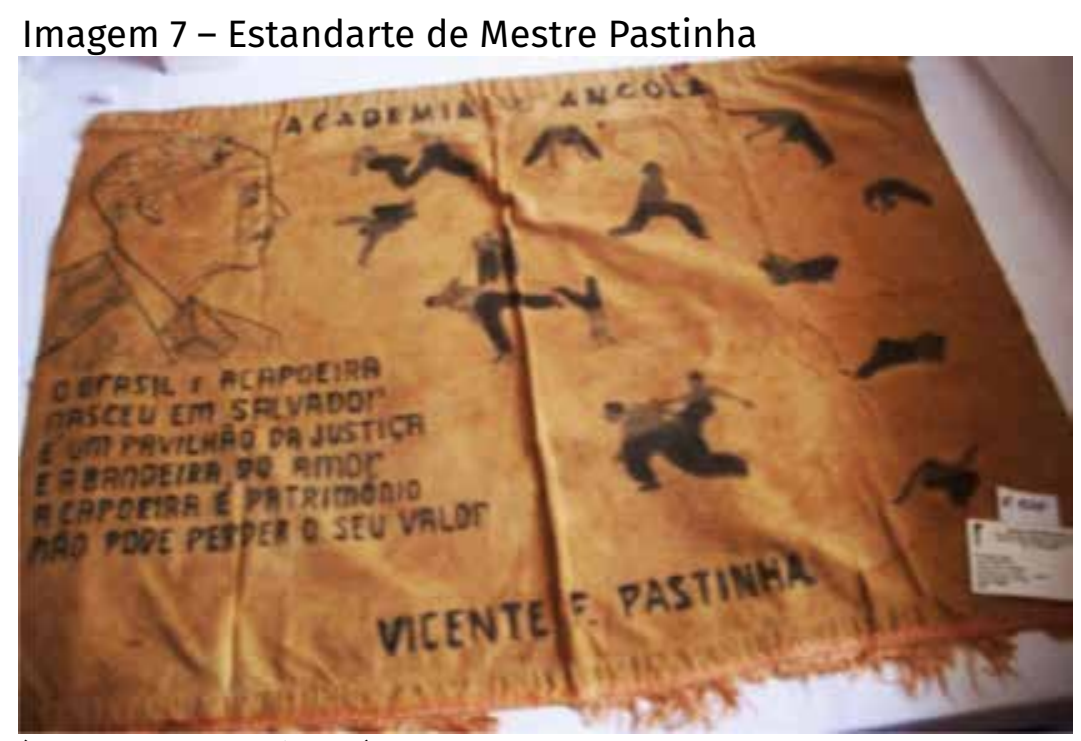

(Acervo do MAFRO/UFBA).

As sábias palavras do Mestre Pastinha, expressas no estandarte acima, apontavam, décadas atrás, para o reconhecimento da capoeira como patrimônio brasileiro e para a necessidade de cuidados com a sua preservação, para que seu "valor" não se perdesse. Entre os argumentos valorativos destacam-se as memórias, trazidas nos corpos e mentes da gente africana, escravizada pelo sistema colonial-escravista, responsáveis pela criação e recriação do que se constitui como "cultura nacional". Neste sentido, a capoeira, como uma das formas de expressão cultural, sintetiza elementos das rítmicas musicais, dos instrumentos e vozes, através do jogo de corpo, que se transforma em dança ou luta. Assim, a premissa de reconhecimento - gravada no estandarte da Academia do mestre - veio a se oficializar em 2008, quando a roda de capoeira foi reconhecida pelo IPHAN (Instituto do Patrimônio Histórico e Artístico Nacional) como patrimônio cultural do Brasil e, em 2014, pela
UNESCO (Organização das Nações Unidas para a Educação, a Ciência e a Cultura), como Patrimônio Imaterial da Humanidade. ${ }^{6}$

Destacou-se, também, no conjunto das peças do Mestre Pastinha, o Livro de Registro do Centro Esportivo de Capoeira Angola (CECA), utilizado entre os anos de 1946 e 1970. No livro, constam as inscrições dos alunos que por ela passaram, dentre eles muitos mestres reconhecidos, nacional e internacionalmente. Esses dados são fontes valiosas de informação para se compreender a abrangência social da capoeira, contribuindo também para a análise estatística das informações referentes à idade, cor, gênero, profissão e religião dos discípulos.

6 "A 9ạ Sessão do Comitê Intergovernamental para a Salvaguarda aprovou, em novembro de 2014, em Paris, a Roda de Capoeira, um dos símbolos do Brasil mais reconhecidos internacionalmente, como Patrimônio Cultural Imaterial da Humanidade". Disponível em: <http://portal.iphan.gov.br/pagina/detalhes/66>. Acesso em: 1 ago. 2016. 
Imagens 8 e 9 - Livro de Registro do CECA,

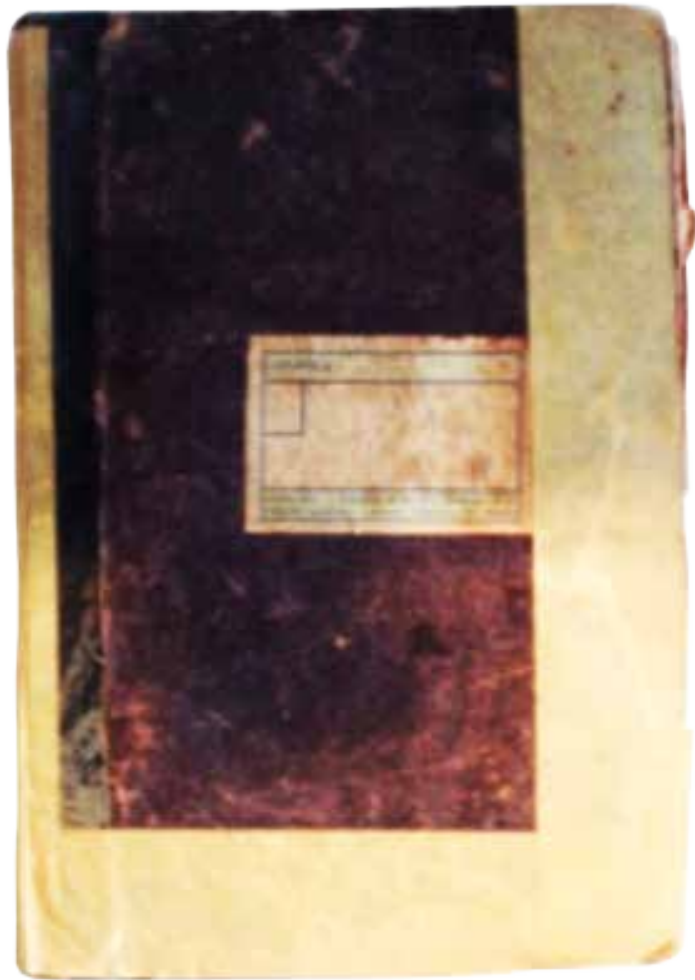

(Acervo do MAFRO/UFBA).

A Coleção Mestre Bimba, composta por 21 peças, expressa a sua grande preocupação em tirar a capoeira da clandestinidade, pois, desde o final do século XIX, era considerada crime, previsto no artigo 402 do Código Penal da República (1890), que punia com até seis meses de prisão aquele que a praticasse, nas ruas ou nas escolas de capoeira, como informa Santos (2002). A coleção mostra a sua luta pela transformação da capoeira em uma manifestação cultural que, além de esporte e dança folclórica, fosse também um estilo revolucionário, segundo Campos (2006).

A Coleção Mestre Bimba não possui nenhum instrumento musical, porém é rica em pôsteres, cartazes, fotografias pessoais, convites de formatura de capoeira, entre outros objetos. Chama a atenção uma fotografia em que o Mestre é cumprimentado pelo então presidente da República, Getúlio Vargas, no Palácio do Catete, no Rio de Janeiro, testemunhando o alto grau de prestígio que Mestre Bimba conquistou nos círculos políticos, em sua luta para capa e primeiro registro do Mestre Pastinha

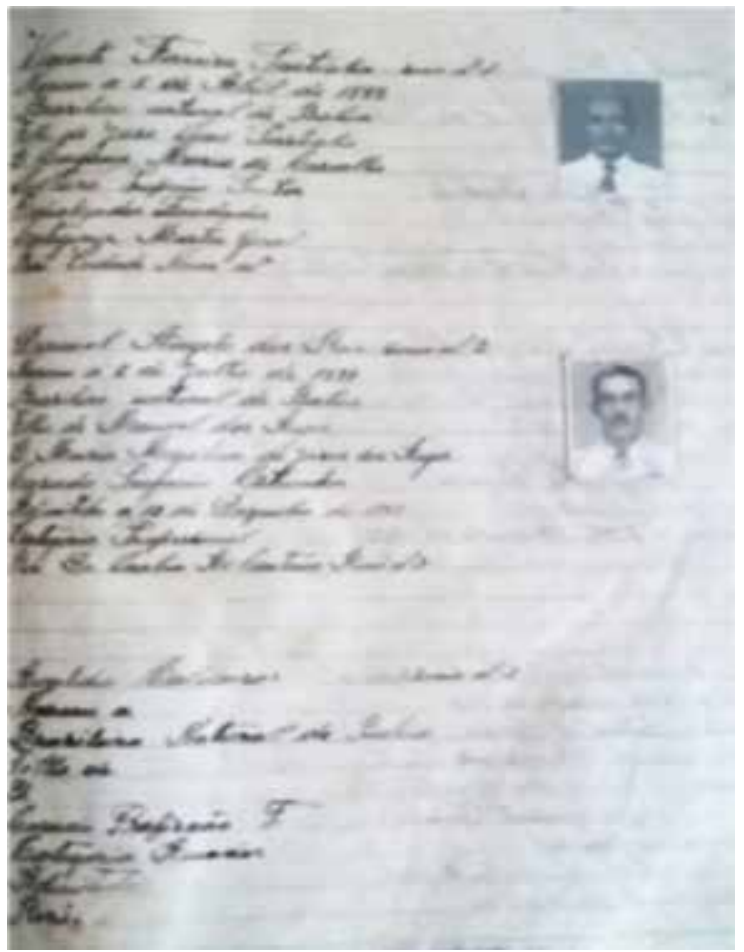

transformar a capoeira em um esporte reconhecidamente nacional.

Imagem 10 - Mestre Bimba com Getúlio Vargas

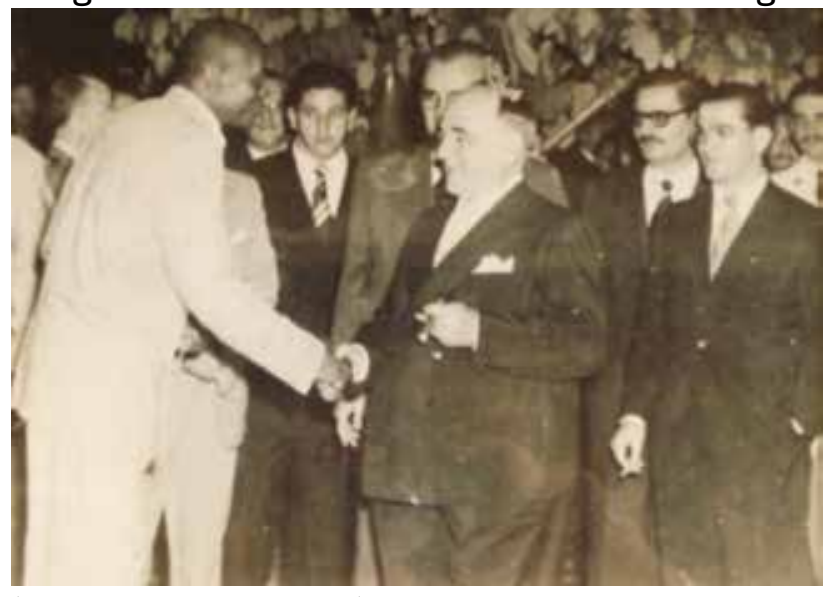

(Acervo do MAFRO/UFBA).

A Coleção Mestre Cobrinha Verde, composta por 26 peças, é marcada pela sua expressão religiosa, com quadros e instrumentos musicais pintados pelo Mestre, com predomínio das cores verde e amarela, que revelam a importância dos elementos cívicos de brasilidade da capoeira na Bahia. Entre as variadas peças, destacam-se imagens iconográficas, que 
remetem ao sincretismo religioso; berimbaus; e um reco-reco feito a partir de uma calota de automóvel, também completamente pintado com cores da bandeira brasileira.

Imagens 11 e 12 - Pintura atribuída ao Mestre Cobrinha Verde e interior do reco-reco de calota de automóvel

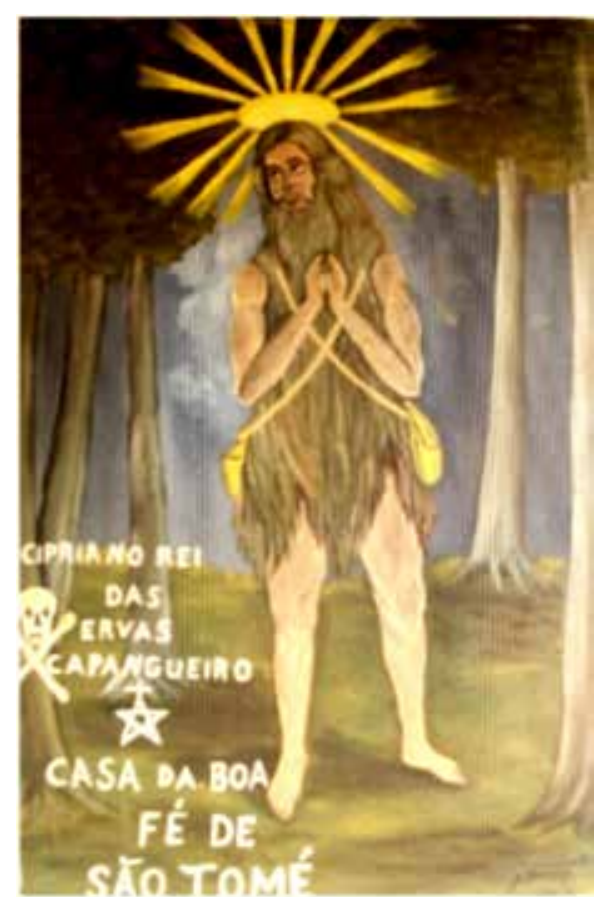

(Acervo do MAFRO/UFBA).
O Museu Afro-Brasileiro (MAFRO/UFBA) é resultante de muitos anos de amadurecimento de ideias dos intelectuais responsáveis pela criação do Centro de Estudos Afro-Orientais (CEAO), que, desde a sua criação, em 1959, já anunciava o desejo de criar um museu. 0 projeto iniciou-se, de fato, em 1974, sendo o museu inaugurado somente a 7 de janeiro de $1982,{ }^{7}$ no prédio da Faculdade de Medicina, localizado no Terreiro de Jesus. Desde os seus primórdios, o MAFRO destaca-se por sua articulação com a comunidade que representa, uma vez que se constitui como um museu universitário responsável pelo registro e a guarda do patrimônio africano e afro-brasileiro na cidade de

7 O CEAO, sob a direção de Guilherme Souza Castro, firmou, em 1974, um convênio com a Universidade Federal da Bahia, os ministérios das Relações Exteriores e da Educação e Cultura, o Governo do Estado da Bahia e a Prefeitura da Cidade do Salvador, que estabelecia a criação do Museu Afro-Brasileiro (CUNHA, 2006). O projeto museológico foi coordenado pela museóloga Jacyra Oswald, e, no momento da inauguração, o CEAO era dirigido pela etnolinguista Yeda Pessoa de Castro.

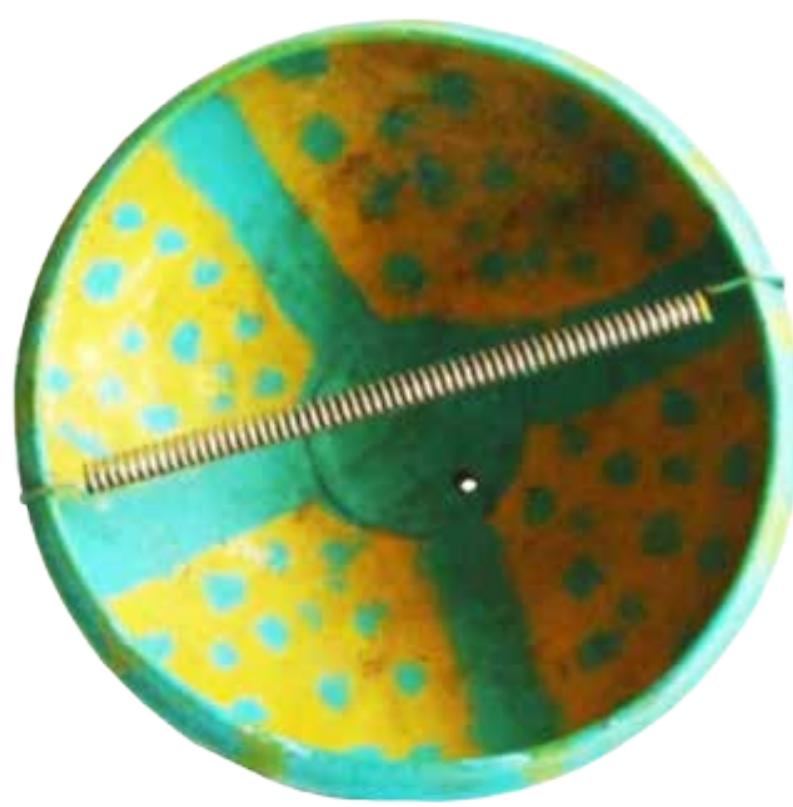

Salvador. A sua criação, nos anos oitenta do século passado, significou, para as comunidades de terreiro, associações de blocos afros e afoxés, para os grupos de capoeira e para as entidades do movimento negro, a possibilidade de visualizar, em exposição museográfica, em uma instituição oficial de salvaguarda do patrimônio cultural, as heranças africanas e afro-brasileiras.

$O$ acervo do MAFRO cresceu a partir dos objetos adquiridos pelo etnólogo Pierre Verger, em sua viagem, a serviço da Universidade, à África, e também através de diversas doações de embaixadas africanas, de colecionadores particulares, organizações internacionais, a exemplo do Museu de Tervuren, na Bélgica, que doou uma coleção de doze cópias de importantes peças do seu acervo, ainda nos anos sessenta, por solicitação do fundador do CEAO, o prof. Georges Agostinho da Silva. É relevante observar a efetiva participação, com a doação de objetos, daqueles a quem o museu buscava retratar. 
Os objetos dos Mestres de Capoeira passaram por um processo de sistematização, que deu ênfase às características iconográficas, sendo assim classificados:

1. Instrumentos musicais (berimbaus, caxixis, pandeiros e reco-recos);

2. Fotografias;

3. Fotomontagem (diversas fotografias reunidas em painel);

4. Documentos escritos (livros, fichas e carteiras de identificação de alunos de escolas de capoeira);

5. Indumentárias (camisas, calça, chapéus e bengalas);

6. Utensílios (banco e armas de madeira);

7. Artefatos artísticos (pinturas feitas pelos Mestres);

8. Insígnias (medalhas e troféus).

Os textos para o livro-catálogo foram produzidos de forma coletiva, reunindo estudiosas(os), pesquisadoras(es), professoras(es) e capoeiristas - em sessões de grupo focal, denominadas Rodas de Conversa sobre a Coleção Capoeira do MAFRO, que funcionaram como fóruns de discussões nos quais foram apresentadas novas informações sobre a vida dos Mestres e de seus objetos e/ou artefatos, assim como novos questionamentos, que vinham à tona, tendo em vista que o campo cultural é pulsante e aberto a novas interpretações. A dinâmica das Rodas de Conversa foi baseada na roda de capoeira e nas outras tantas rodas de memórias do povo negro. Nesses encontros, destacam-se a vivência e a compreensão da capoeira como um fenômeno sociocultural; e o conceito de cultura como dialético, sem hierarquias e oposições binárias, entre o popular e o erudito, como ponderam as argumentações de Hall (2003, p. 341-342) sobre a cultura negra: “[...] nunca pode ser simplificada ou explicada nos termos das simples oposições binárias habitualmente usadas para mapeá-la [...]".
Nessa perspectiva, o MAFRO/UFBA, ao realizar a nova sistematização documental, base para a nova expografia para a Coleção de Capoeira, destaca o caráter autobiográfico dos três mestres, oferecendo ao seu público um importante conjunto documental, apresentando uma série de dados que levaram à identificação de cada mestre, com a explicitação de suas diferentes formas de praticar e registrar a capoeira.

A realização de pesquisa é fundamental para a constituição do fazer museológico, como bem salienta Chagas (2005, p. 59): “[...] os museus são casas de pesquisa". No caso da construção coletiva do livro-catálogo, a pesquisa possibilitou a realização do trabalho de revisão e sistematização dos registros propriamente museológicos, ações museológicas comprometidas com o estudo dos objetos museais, de forma a ultrapassar o campo das informações meramente intrínsecas, adentrando o campo extrínseco, através do exercício de conexão entre os objetos e/ou artefatos e suas memórias. Neste rico processo, discussões teóricas e analíticas concernentes ao campo museal foram debatidas, com o objetivo de enriquecer as abordagens teóricas e metodológicas para o planejamento de uma futura exposição, tendo em vista que a expografia, a parte mais visivel dos museus, tem importância estratégica, cabendo a esta, como assinala Cury (2005, p. 368): “[...] a maior responsabilidade por mediar a relação entre o homem e a cultura material".

O livro-catálogo e a nova exposição oferecerão ao público um importante conjunto documental, como fonte de informações das memórias afro-brasileiras. Os acervos dos Mestres Pastinha, Bimba e Cobrinha Verde - antes pertencentes à categoria de acervos individuais, ao adentrarem o espaço museal adquiriram o status de acervos coletivos e autobiográficos, passiveis de novas interpretações dos seus significados, destinados ao grande público. 
O estudo da Coleção de Capoeira do MAFRO articula-se ao campo museológico que prima pelas ações de pesquisa de acervos institucionais, colaborando para a construção de novas reflexões e potencialidades para o incremento de ações museais, tais como documentação, conservação, ação educativa e cultural e expografia, em que possam ser destacadas as diversas tramas sociais, para além da descrição formal dos objetos. Nesta perspectiva, o estudo dessa coleção se entrelaça às relações sociais e culturais vivenciadas pelos mestres, constituindo-se como um referencial da memória afro-brasileira. Os objetos, com suas marcas de uso, revelam histórias de vida que neles estão impregnadas, registros que rememoram e revelam as distintas formas de luta pelo reconhecimento social e político da capoeira.

Nesse processo de pesquisa museológica, foram seguidos caminhos metodológicos em busca da compreensão das dinâmicas culturais que configuram a capoeira como uma herança cultural afro-brasileira, como um patrimônio que "[...] não pode perder o seu valor", como alertam as palavras do Mestre Pastinha no estandarte da sua Academia. Ao analisar dinâmicas culturais, como a capoeira, é preciso não esquecer o contexto de sua criação, a sociedade escravista colonial e seus desdobramentos racistas pós-coloniais, no qual mulheres e homens tiveram que se reinventar, como assinala Zapata Olivella (1989, p. 110): “[...] o negro devia fabricar sua própria bússola, improvisando-a a partir de sua dor, de sua memória ancestral, de seu poder criador. Foi o que fez com sua filosofia, seus mitos e experiências". A manutenção da prática da capoeira é um exemplo do "poder criador" dos afrodescendentes, que, utilizando a "bússola" de suas memórias ancestrais, construíram novas formas de sociabilidade e de sobrevivência no chamado novo mundo.

A constituição das coleções autobiográficas pode também ser compreendida a partir da perspectiva da demolição de mitos, apontada por Frantz Fanon (2008, p. 109): “Os pretos são selvagens, estúpidos, analfabetos. [...] essas afirmações eram falsas. Havia um mito do negro que era preciso, antes de mais nada, demolir". Como "demolidores" de preconceitos, esses três homens negros, que vivenciaram o racismo institucional explícito, conseguiram provar para a sociedade a importância da capoeira que praticavam, e com muita sensibilidade conseguiram registrar, em suportes diversos, a história da capoeira baiana e sua relação com a cultura nacional, bem como sua expansão internacional.

Esse embate permanente entre esquecimento e memória, que se deu e se dá, ao longo da história dos africanos, em seus territórios de diáspora, tem por característica a busca de estratégias que permitam reviver e reavivar aspectos que são importantes para a identidade individual e coletiva.

Sabe-se que um dos últimos atos violentos infligidos a centenas de milhares de homens, mulheres e crianças, antes de seu sequestro, desterritorialização e embarque rumo ao "Novo Mundo", era a obrigação de dar voltas em torno da "Árvore do Esquecimento". Os algozes imaginavam que com isso plantariam o esquecimento nas cabeças, corações e almas dos indivíduos que subjugavam. Naquele momento dramático, homens e mulheres eram obrigados a deixar para trás não apenas as lembranças, mas, entre outras coisas - e sobretudo -, as suas famílias, amores, seus mortos, objetos pessoais e sagrados, propriedades e lugares ocupados em suas sociedades de origem, pois eram esposas, maridos, agricultores, caçadores, pescadores, ferreiros, guerreiros, feiticeiros, artistas, entre tantas formas de ser e estar nas sociedades africanas.

Embarcavam seminus, e ali, naqueles navios que os levariam para viagens sem retorno, sofriam o golpe fatal, quando até o ar puro e o 
contato com a natureza lhes eram confiscados. Concretizava-se naquele momento o desterro, o golpe final, em que eram cortados os laços físicos com o seu território de origem. Concretizava-se, ou tentava-se concretizar, o processo de animalização dessas centenas de milhares de seres humanos.

Iniciada a viagem, a terra firme tornava-se mar, e o trajeto era marcado pela incerteza e pelas vagas que prenunciavam o cruel destino a eles reservado. 0 chão natal pisado outrora por seus pés dava então lugar à liquidez profunda, que, para muitos deles, se transformou em túmulo, antes mesmo da chegada ao destino final.

Em meio ao espanto, assombro, medo e incerteza, que reinavam nos porões e tombadilho daquelas naus malditas, seguiam para o outro lado da margem. Passageiros solitários, abandonados à própria sorte. Pelo menos era isso que se imaginava e que se concebia na perspectiva imediata e material daquela travessia. No entanto, ainda que estivessem protegidas por Nossa Senhora do Rosário e tantas outras divindades cristãs, aquelas embarcações levavam passageiros poderosos, que velavam pela sorte daqueles seus filhos inglórios e humilhados, mantidos acorrentados nos porões negreiros, pois seguiam com eles: Voduns, Inquices, Orixás e Alá, com suas armas e braços para proteger e acalentar os seus daquele momento em diante. E dali em diante, jamais os abandonariam na vida.

Chegados à terra firme, novas rupturas e violências se davam, pois os últimos laços ainda mantidos na travessia, bem como os novos, estabelecidos na embarcação, eram rompidos por conta das distribuições daquelas "peças" humanas entre os seus compradores, futuros donos dos seus destinos. Foram tantas e tão contínuas as violências e privações que esses indivíduos e seus descendentes sofreram nesta terra da Santa Cruz que o mais provável seria que, ao fim do infame comércio que os trouxe para este lado do Atlântico, os mesmos fossem exterminados e varridos da sociedade brasileira, construída às custas dos seus suores, lágrimas e sangue.

Esse teria sido o final desta história, mas é neste momento que a roda entra em cena. Ao contrário do que criam e desejavam os algozes que aprisionaram africanos do outro lado do Atlântico, fazer com que rodeassem a "Árvore do Esquecimento" não provocou amnésia naqueles homens e mulheres sequestrados, pois a memória estava incrustada na pele, na alma, no coração e nos saberes e vivências de cada um deles. E, pouco a pouco, parte do que foi deixado do outro lado da margem, foi sendo revivido e ressignificado, em rodas.

Para combater a violência real, provincial, imperial e republicana, veio a roda. Surgiu a capoeira, com ginga e mandinga, jogada no barro vermelho dos arredores da Casa Grande e da Senzala, entre cana, café, algodão e charque. Também na praça da igreja, na frente das câmaras, nos becos, vielas, nas ruas, beira de praia, mar e rio.

Jogo que contribuiu para devolver altivez e orgulho àqueles que ousaram jogá-lo, a despeito do capataz e do chefe de polícia. Apesar da violência simbólica que os classificava como malandros e vadios.

Jogo que defendeu honras, como, por exemplo, a de mulheres protegidas por ele das mazelas dos senhores violentos e violentadores. Jogo que cobriu a fuga e passou a ser proteção de quilombos e quilombolas, e que segue sendo jogado nos tantos quilombos urbanos contemporâneos, ultrapassando os limites e interdições originais de gênero, jogando para cima a autoestima de mulheres, homens e crianças da cor, mas que, inclusive generosamente, se coloca a serviço de tantas outras cores, mesmo daquela dos algozes de outrora. 
Mas vieram outras rodas. E na calada da noite, no interior das senzalas, no fundo das casas e igrejas, pouco a pouco, em círculos, corpos de homens e mulheres foram cedendo lugar para que os seus ancestrais, aqueles mesmos que embarcaram nas naus, de forma clandestina e cuidadosa, pudessem, enfim, se materializar entre nós. E assim poder cuidar das feridas e dar proteção e perspectiva de futuro aos seus filhos, restituindo, desse modo, os laços de família originais que tinham se rompido com o sequestro e a violência do tráfico. Juntaram-se a eles os donos da terra, aqueles que acolheram de braços abertos os filhos de África, surgindo assim uma numerosa família formada por Inquices, Voduns, Orixás, Caboclos e Encantados. A cada dia que esta roda se renova se dá o misterioso fenômeno de união de passado, presente e futuro de um povo, anulando, em certa medida,

\section{Referências}

CAMPOS, Hélio José B. C. de. Histórias da Academia de Mestre Bimba: o cotidiano da aprendizagem. 2006. 310 f. Tese (Doutorado em Educação) - Faculdade de Educação, Universidade Federal da Bahia, Salvador, 2006.

CHAGAS, Mário. Pesquisa Museológica. In: GRANATO, M.; SANTOS, C. P. dos. Museu Instituição de Pesquisa. MAST Colloquia, Rio de Janeiro: Museu de Astronomia e Ciências Afins, 2005. v. 7, p. 11-22.

CUNHA, Marcelo Nascimento B. da. Teatro de memórias, palco de esquecimentos: culturas africanas e das diásporas negras em exposições. 2006. 285 f. Tese (Doutorado em História) - Pontifícia Universidade Católica de São Paulo, São Paulo, 2006.

CUNHA, Marcelo Nascimento B. da. Sobre rodas e memórias. In: FREITAS, Joseania Miranda. (Org.). Introdução. In: Uma coleção biográfica: os Mestres Pastinha, Bimba e cobrinha Verde no Museu Afro -Brasileiro da UFBA. Salvador: EDUFBA, 2015. p. 141143. o vasto território líquido que separa as duas margens de um mesmo território histórico e ancestral.

Mas veio ainda outra roda, aquela da liberação do corpo em festa e samba, ainda que as outras duas também sejam libertadoras e festivas, que busca aplacar tanta dor ancestral que insiste, por vezes, em doer. Passos coreográficos, palmas e música cadenciam corpos, almas e corações e trazem, mais uma vez, memórias passadas, permitindo construir futuros. Desta roda e dos seus ritmos marcados muitos outros surgiram, assim como muitas outras formas de coreografar os passos no chão. Inclusive saindo da roda original, ganhando as ruas e parando o mundo em tantas festas e carnavais.

Assim, a partir dessas e tantas outras rodas possíveis, o mundo roda, o tempo roda, a memória roda. E o povo negro segue. Rodando.

CURY, Marília. Comunicação e pesquisa de recepção: uma perspectiva teórico-metodológica para os museus. São Paulo: História, Ciências, Saúde - Manguinhos, v. 12, suplemento, 2005.

FANON, Franz. Pele negra, máscaras brancas. Tradução de Renato da Silveira. Salvador: EDUFBA, 2008.

FREITAS, Joseania Miranda. Introdução. In: FREITAS, Joseania Miranda. (Org.). Uma coleção biográfica: os Mestres Pastinha, Bimba e cobrinha Verde no Museu Afro-Brasileiro da UFBA. Salvador: EDUFBA, 2015. p. 15-24.

GONÇALVES, José Reginaldo S. Antropologia dos objetos: coleções, museus e patrimônios. Rio de Janeiro: Editora Garamond. 2007. Disponível em: <http:// naui.ufsc.br/files/2010/09/antropologia_dos_objetos V41.pdf>. Acesso em: 02 jul. 2016.

HALL, Stuart. Da diáspora: identidades e mediações culturais. Trad. Adelaine La Guardia Resende. Belo Horizonte: UFMG Editora, 2003. 
MENESES, Ulpiano Toledo Bezerra de. Memória e cultura material: documentos pessoais no espaço público. Estudos Históricos: memória e cultura material, Rio de Janeiro, CPDOC/Fundação Getúlio Vargas, v. 11, n. 21, p. 89-103, 1998. Disponivel em: <http://virtualbib.fgv.br/ojs/index.php/reh/article/viewArticle/2067>. Acesso em: 01 jul. 2016.

SANTOS, Esdras Magalhães dos. Mestre Damião. A verdadeira história da criação da luta regional baiana do Mestre Bimba. São José dos Campos, 2002. Disponivel em: <http://www.cppa.com.br/attachments/File/Artigos/LUTA REGIONAL BAHIANA DO MESTRE_BIMBA.pdf>. Acesso em: 01 jul. 2016.
SOUZA, Elizeu Clementino. (Auto)biografia, histórias de vida e práticas de formação. In: NASCIMENTO, A. D., HETKOWSKI, T. M. (Orgs.). Memória e formação de professores. Salvador: EDUFBA, 2007. p. 59-74. Disponivel em: <http://books.scielo.org/id/f5jk5/pdf/ nascimento-9788523209186-04.pdf>. Acesso em: 04 jul. 2016.

ZAPATA OLIVELLA, Manuel. Las claves mágicas de América. 2. ed. Bogotá: Plaza \& Janés, 1989.

Recebido em: 03.08.2016

Aprovado em: 02.10.2016

Joseania Miranda Freitas é Doutora em Educação pela FACED/UFBA/2001. Universidade Federal da Bahia/Docente do curso de Museologia - graduação e pós; pesquisadora do Museu Afro-Brasileiro-UFBA. Grupo de Pesquisa Observatório da Museologia Baiana/PPGMuseu. e-mail: joseaniafreitas@yahoo.com.br.

Rua Aristides Novis 197. Federação. 40210-909. Salvador Bahia. (71) 988058486.

Marcelo Nascimento Bernardo da Cunha é Doutor em História PUC-SP/2006. Professor da Universidade Federal da Bahia, Coordenador do Programa de Pós-Graduação em Museologia; pesquisador do Museu Afro-Brasileiro-UFBA. Grupo de Pesquisa Observatório da Museologia Baiana /PPGMuseu. e-mail: marcelo.bernardodacunha.cunha@gmail.com.

Rua Aristides Novis 197. Federação. 40210-909. Salvador Bahia. (71) 988552302. 